La Cueca según Pablo Garrido: Entre el compromiso Político-Cultural y un decreto dictatorial (1928-1979)

La Cueca according to Pablo Garrido: Between the Political-Cultural commitment and a dictatorial decree (1928-1979)

Pp. 56 a 83

\title{
LA CUECA SEGÚN PABLO GARRIDO: ENTRE EL COMPROMISO POLÍTICO-CULTURAL Y UN DECRETO DICTATORIAL (1928-1979)
}

\author{
LA CUECA ACCORDING TO PABLO GARRIDO: BETWEEN THE \\ POLITICAL-CULTURAL COMMITMENT AND A DICTATORIAL DECREE
}

(1928-1979)

\author{
Dra. (c) Karen Donoso Fritz \\ Universidad de Santiago \\ Universidad Alberto Hurtado \\ Chile \\ Dr. Ignacio Ramos Rodillo \\ Universidad Mayor \\ Chile $^{*}$
}

\section{INTRODUCCIÓN}

El 18 de septiembre de 1979, el dictador Augusto Pinochet firmó el Decreto Supremo № 23, que declaró a la cueca "danza nacional de Chile". La ceremonia se realizó en el Edificio Diego Portales y dentro de su programa, se incluyó la presentación del libro Historial de la Cueca, del reconocido autor nacional Pablo Garrido Vargas (1905-1982), como publicación oficial de la Secretaría de Relaciones Culturales de la Presidencia de la República. Este hecho no tendría nada de excepcional, si no fuera porque siete años antes, Garrido fue exonerado de su cargo como funcionario del Departamento de Cultura de la Presidencia del derrocado gobierno de Salvador Allende.

La trayectoria de este investigador es vasta. Fue uno de los compositores,

Correos electrónicos karen.donoso@usach.cl ORCID 0000-0003-3397-5990, ignacio.ramos@umayor.cl ORCID, 0000-0002-3361-3925 Artículo recibido el 1/04/2021 y aceptado por el comité editorial el 20/07/2021. Este artículo es producto del proyecto 484628 "Pablo Garrido y el folclor musical chileno", financiado por el Fondo de la Música, Ministerio de las Culturas, las Artes y el Patrimonio, Gobierno de Chile, convocatoria 2019. 
intérpretes y musicólogos más controversiales y vanguardistas del siglo $\mathrm{XX}$ chileno. Destacó como uno de los primeros dirigentes sindicales del gremio musical, como crítico acérrimo de la institucionalidad académica de la música nacional; dedicó varias décadas de trabajo al periodismo y la crítica cultural; como burócrata realizó más de una campaña por la promoción de la música chilena en la industria musical y llamó la atención de músicos y compositores por la investigación y promoción de la música popular, tomando como bandera de lucha el estudio y promoción de las tradiciones de raigambre popular, indígenas y afroamericanas.

Asimismo, fue funcionario de los gobiernos del Frente Popular y la Unidad Popular, con proyectos que implicaban ampliar el papel del Estado en el campo cultural. Por ello cabe preguntarse; ¿cómo fue posible que la obra de un músico e intelectual comprometido con la izquierda chilena fuera patrocinada por la dictadura que interrumpió y revirtió abruptamente el proceso político del que fue parte?

Este artículo pretende analizar parte de sus escritos, inéditos y publicados, puntualmente sobre la cueca, así como su interpretación de las políticas culturales públicas, con énfasis en los acontecimientos, procesos e ideas que lo implicaron en la promulgación del mencionado Decreto № 23. Sobre su figura se ha escrito escasamente. Sólo Fernando García ha redactado una completa biografía, aún inédita, que sirvió de base para esta investigación. ${ }^{1}$ Otros investigadores lo han abordado a partir de su epistolario ${ }^{2}$ o bien dentro de estudios específicos sobre jazz o sobre actividad sindical, ámbitos donde Garrido fue un puntal. ${ }^{3}$ Con dichas investigaciones como base, en este artículo lo abordaremos como un intelectual, es decir, como una persona que piensa y comunica su pensamiento, creador o mediador y ubicado en un debate político, comprometido con una posición, en nuestro caso, sobre lo político-cultural. ${ }^{4}$

Como hipótesis, proponemos que la dictadura militar no contó con un proyecto artístico-cultural propio y original, de modo que debió reconocer tradiciones artísticas y trayectorias intelectuales preexistentes, incluso mediante la apropiación. En el campo del folclor, la dictadura promovió una versión nacionalista despolitizada, concibiéndolo como un patrimonio común

1 Facultad de Artes, Universidad de Chile. Fondo Pablo Garrido (FPG), Fernando García Arancibia. Pablo Garrido. Santiago de Chile, manuscrito inédito, ca. 1990.

2 González, Juan Pablo (1983). “Cronología epistolar de Pablo Garrido”, Revista Musical Chilena, XXXVII, 160, pp. $4-46$.

3 Menanteau, Álvaro (2006). Historia del Jazz en Chile. Santiago: Ocho Libros Editores; Cabello, Pablo (2020). Historia del jazz en Valparaíso: los albores (1920-1934). Tesis para optar al grado de Magíster en Historia. Pontificia Universidad Católica de Valparaíso, Valparaíso; Karmy, Eileen (2019). The path to trade unionism: musical work in Chile (1893-1940). Tesis para optar al Grado de Doctora en Filosofía. Universidad de Glasgow. Glasgow

4 Ory, Pascal y Jean-Francois Sirinelli (2007). Los intelectuales en Francia. Del caso Dreyfrus a nuestros días. Valencia: Ed. PUV, pp. 20-21. 
a todos los grupos sociales y, por tanto, asociado estrechamente a la identidad nacional y lejano a las perspectivas clasistas promovidas por la izquierda durante el gobierno de la Unidad Popular. Bajo esta noción, asumimos que la dictadura cooptó y utilizó la obra y el prestigio de Pablo Garrido, toda vez que el musicólogo definió la cueca desde una perspectiva que no entraba en conflicto con la perspectiva cultural autoritaria. Por su parte, el investigador, si bien manifestó su compromiso con una noción nacional y popular del arte y del folclor -y con un papel del Estado activo en cultura-, hacia mediados de la década de 1970 superaba los setenta años de edad, se encontraba cesante, no tenía pensión ni otro medio de subsistencia y vivía de la solidaridad de su familia y amigos, situación que lo impulsó a aceptar este trato por conveniencia.

Esta investigación utilizó como fuentes principales, los documentos del Fondo Pablo Garrido, resguardado por el Departamento de Música de la Facultad de Artes de la Universidad de Chile. Este acervo fue organizado por el propio autor, entre 1978 y 1980, quien pretendía venderlo a alguna institución pública como la Biblioteca Nacional de Chile o la Biblioteca del Congreso Nacional. ${ }^{5}$ Tras su muerte, llegó a dependencias de la Facultad en 1984, donde fue ordenado por el musicólogo Juan Pablo González y, en la década siguiente, reorganizado y conservado gracias a un proyecto dirigido por Fernando García. Este archivo está a la espera de un proceso de conservación y catalogación de acuerdo a parámetros profesionales, por lo tanto, debemos advertir que en este artículo se utilizó el orden y la numeración de las cajas almacenadas en dichas dependencias entre marzo y diciembre de 2019. Por ello, nuestras referencias conservan los nombres de carpetas, subcarpetas y documentos que el propio Garrido asignó. En el caso de las cartas, utilizamos los nombres de los destinatarios o autores tal como figuran en dichos documentos.

Este artículo constará de tres secciones: en la primera se reseñará el papel de Garrido como intelectual y su compromiso en el diseño e implementación de políticas culturales públicas; en la segunda se abordarán sus tesis respecto a la cueca, relativas a su origen y sus definiciones; y en la tercera se revisarán sus últimos diez años de vida a través de la gestación, producción, publicación y recepción del libro Historial de la Cueca, en el contexto de las políticas culturales de la dictadura, concentrados específicamente en la promulgación del Decreto de nacionalización de la cueca de 1979.

\footnotetext{
En septiembre de 1979 comenta a su familia su intención de vender su archivo y biblioteca personal, y en octubre se los ofrece a la Biblioteca del Congreso Nacional, por \$200.000. Su director, Jorge Hübner, rechaza la oferta por falta de fondos. Luego intenta venderlo a la Biblioteca Nacional, donde tampoco hubo recepción. En: FPG, Caja 72. Carta de Pablo a Richard, 7 de septiembre 1979 y Carta de Pablo Garrido a Jorge Hübner, Santiago, 4 de octubre 1979.
} 


\section{Pablo Garrido y su compromiso político-cultural}

Hacia 1979, Pablo Garrido se carteaba a menudo con su familia. A sus hermanos, sobrinas y sobrinos, quienes se encontraban radicados en México, Australia y los Estados Unidos, les expresaba sus inquietudes: la cesantía, enfermedades y la falta de jubilación lo mantenían en vilo. Sin embargo, se mantuvo incólume en su trabajo. Así le contaba su situación a su ahijada:

"Acá llevo cinco años ya sin salir del país, dedicado a terminar varios libros y a escribir tres nuevas óperas (...) Económicamente, puedes imaginarte (después de haber laborado junto al anterior régimen, aunque sin militancia política alguna), que todo ha sido demasiado negativo (...) Lo importante es que, espiritual, física y moralmente sigo tan firme como siempre."6

Si bien es cierto que no se le conoció militancia, su trayectoria artística e intelectual estuvo estrechamente vinculada a su activismo político y cultural. Y este no se reducía a su participación como funcionario del recién derrocado gobierno de la Unidad Popular, sino que se remontaba por lo menos hasta las décadas de 1920 y 1930, pues Garrido fue uno de los impulsores de las organizaciones gremiales que congregaron a los músicos y compositores nacionales en los años previos al triunfo del Frente Popular.

Según una investigación reciente, este involucramiento estuvo marcada por su propia experiencia laboral, en Chile y el extranjero, y por las impresiones que su hermano Juan Santiago le compartió sobre la protección a los músicos en México. ${ }^{7}$ Cabe destacar su participación en el comité ejecutivo del Sindicato Profesional de Músicos de Valparaíso, y en la organización del Primer Congreso Nacional de los Músicos de Chile (1940), donde se demandó la protección de gremio bajo las leyes sociales. ${ }^{8}$

Así se creó la Confederación de Sindicatos de Músicos de Chile, asociada a la Confederación de Trabajadores de Chile, principal central sindical del país. Aquí, el papel de Garrido fue clave pues estableció alianzas con los dirigentes de esta organización, en ese entonces liderada por comunistas y socialistas. ${ }^{9}$

FPG, Caja 72, Carta de Pablo Garrido a Amparo, Santiago, 27 de octubre 1979.

Karmy, Eileen (2019). The path to trade... p. 192.

En 1924 se promulgaron una serie de leyes para la protección de trabajadores y empleados, tales como la que fijó las condiciones para firmar contratos, la de seguro por enfermedad, invalidez y accidentes, y la que establecía la formación de sindicatos por rama o profesión. En 1931, estas leyes quedaron contenidas en el Código del Trabajo. Ver: Rojas, Jorge (1993). La dictadura de Ibáñez y los sindicatos (1927-1931). Santiago: Dibam.

$9 \quad$ FPG, Fernando García Arancibia. Pablo Garrido... pp. 73-74; Garcés, Mario (2018). El movimiento obrero y el Frente Popular (1936-1939). Santiago: Ed. Lom, p. 125. 
En paralelo, formó parte de la Alianza de Intelectuales, organización internacionalista y antifascista que se sumó al Frente Popular. ${ }^{10}$ A Garrido le correspondió la tarea de establecer acuerdos entre la Alianza y organizaciones de estricto carácter musical. ${ }^{11}$

En suma, hacia 1940 se perfilaba como un activo intelectual de izquierda en el contexto de un gobierno de heterogeneidad partidaria, que esperaba establecer alianzas amplias y que tenía entre manos un proyecto de democratización de la educación y las artes, así como de reconocimiento de expresiones artísticas populares. Con este trasfondo incrementó la frecuencia de publicaciones a través de la prensa, dando cuenta de su posición con respecto a las implicancias sociopolíticas del arte y la cultura, al papel de los artistas en la contingencia política y el estado de desarrollo cultural del país. De hecho, y como muestra de su compromiso con la democratización del arte, increpó en varias ocasiones a los músicos doctos por no crear obras orientadas al gusto y la comprensión populares:

\begin{abstract}
"Prefieren nuestros músicos especular con las tendencias del dernier cri europeo a bucear en el alma del pueblo. Escriben obras sobre temas campesinos donde el hombre del pueblo no se identifica, músicas para mezquinas «elites», composiciones de méritos, pero donde la masa no halla el solaz a que tiene derecho a gozar [...] De nada nos servirán los conciertos sinfónicos, los cuartetos de cuerdas, las audiciones «culturales» si ellas van dirigidas al núcleo de pseudo amantes del arte. No es esa la labor que necesitamos hacer. Hay que crear los equipos de divulgadores que entren a la fábrica, que vayan a la escuela, al club de deportes, al club obrero, a los barrios llamados pobres por la estupidez de los bolsillos llenos de oro mal avenido. ${ }^{12}$
\end{abstract}

Estos alegatos, obedecen a la crítica que Garrido lanzaba contra la dirección que la música académica tomaba durante la primera mitad del siglo XX. No sólo criticaba el eurocentrismo que en general cundía entre los compositores -con las notables excepciones de Allende, Isamitt, sí mismo y algunos otros-, sino sobre todo el carácter autonomizado del arte musical que, desde la Universidad de Chile, ejercía un dominio de la escena difícilmente contrarrestable. A través de sus actividades como crítico, periodista, investigador y sindicalista, Garrido advirtió esta situación, anteponiendo las categorías analíticas de "función social de la música" y "arte burgués" y actuando, por ejemplo, en abierto desafío a normas estéticas como la de la separación radical de tradiciones doctas, populares y tradicionales.

\footnotetext{
10 Moraga, Fabio y Peñaloza, Carla (2011). “España en el corazón de los chilenos. La alianza de intelectuales y la revista Aurora de Chile, 1937-1939", Anuario Colombiano de Historia Social y de la Cultura, 38, 2, pp. 55-81. Consultado el 2 de marzo 2021.

11 Karmy (2019) The path to trade..., pp. 193-194.

12 FPG, Escritos Tomo 1. Pablo Garrido, Música para el pueblo, 1933.
} 
Para él, la orientación social de la cultura no pasaba solamente por la protección laboral de los músicos o la aplicación de políticas culturales, si no además por el conocimiento y la exaltación de las tradiciones nacionales. Algunas de estas reflexiones quedaron de manifiesto en su panfleto: Tragedia del músico chileno (1940) donde, con motivo de lo anterior, declaraba que: "[...] nos han enseñado a nosotros los músicos, a odiar y temer nuestra propia música. Para hacerla tenemos que escondernos bajo caretas ridículas y perniciosas. Duro es confesarlo, pero hay que decirlo de una vez por todas."13

Las implicancias políticas e identitarias de la producción escrita de Garrido son multidimensionales, atravesando toda su obra intelectual y creativa como temas basales, al menos hasta inicios de la década de 1970. Sus convicciones ya se hallaban maduras en la década de 1940, siendo expresadas indistintamente en sus escritos referidos tanto al jazz y la música académica como al folclor. Consideraba a la música un solo gran patrimonio que forzosamente debía adquirir un carácter socialmente comprometido. Por ejemplo, consideraba que:

\begin{abstract}
“Ningún artista, creador o intérprete, puede estar al margen de la realidad política actual. Formamos la superestructura de la sociedad, es decir, la estructura superior, no en sentido clasista, sino en el hondo sentido filosófico y social. El arte es una función social. La insensibilidad de los hombres que manejan la herramienta estética, provoca el divorcio entre la cultura y la sociedad; por este crimen innombrable las grandes masas laboriosas han sido negadas al deleite estético, que no es expresión suntuaria, sino eje de la personalidad humana." ${ }^{14}$
\end{abstract}

Parte de sus aprehensiones referían a la responsabilidad estatal en la difusión y promoción de las artes nacionales y populares, teniendo en cuenta que estos asuntos ya interesaban a la institucionalidad desde la dictadura del general Ibáñez. De hecho, en referencia al varguismo brasilero, declaraba que:

\footnotetext{
“Durante nuestros viajes, hemos tenido oportunidad de ver cómo desarrollan dicha propaganda los gobiernos de otros países. Hemos recibido de manos de diversas autoridades, folletos, libros y ediciones musicales, todas publicadas por los diversos estados, con el fin de propagar la canción nativa [...] ¿Por qué nuestras autoridades no siguen el ejemplo de los gobernantes de otros países? Es cierto que hasta ahora se ha despreocupado casi absolutamente de la música popular nuestra; también es cierto que en Chile no se cantan canciones chilenas, sino canciones de otros cielos hermanos, pero también es cierto que esto mismo debiera servirnos de reprimenda." ${ }^{\prime 15}$
}

3 Garrido, Pablo (1940). Tragedia del músico chileno. Santiago: Editorial Smirnow, p. 11.

14 FPG, Escritos Tomo 2. Pablo Garrido, "El artista en la hora actual", El Siglo, 3 de septiembre 1946.

15 FPG, Escritos Tomo 1. Pablo Garrido, "El Estado debe editar nuestras canciones como un medio de propaganda", Las Últimas Noticias, 29 de julio 1939. 
Esto que observaba en el ámbito de la música, lo proyectó hacia otros espacios culturales y, con la esperanza que el Frente Popular se pronunciara al respecto, en 1939 publicó un listado de medidas públicas: crear centros de difusión musical en los barrios populares que, a su vez, formaran coros, conjuntos y orquestas locales; que se promovieran concursos de cantantes criollos, de música popular, de: "[...] cantos de masas, de canciones revolucionarias, donde el poeta y el músico fundan sus fervores para que nuestro pueblo cante lo suyo."16

Asimismo, que se crearan orquestas sinfónicas que permitieran el perfeccionamiento de sus integrantes: "para interpretaciones concienzudas a una masa que deberá aprender a conocer desde lo que es un violín y por qué hay tal variedad de instrumentos en un conjunto de dicha naturaleza."17

Años más tarde, fue incorporado como funcionario de la Dirección General de Informaciones y Cultura (DIC). La oficina había sido creada en 1942 por el gobierno de Juan Antonio Ríos, con el fin de cumplir labores de información y propaganda y supervisar los organismos: "[...] mediante los cuales el Estado cumpla su función de hacer llegar a los habitantes del país los medios de esparcimiento y los beneficios culturales que no se impartan por el Ministerio de Educación Pública", ${ }^{18}$ bajo la noción de "democratización" del arte y la cultura.

Se aprecia que la DIC recogió las demandas de los artistas e intelectuales que visualizaban al Estado como principal agente cultural, en una lógica coincidente a las del Estado Empresario o Estado de Compromiso, desarrolladas bajo regímenes desarrollistas latinoamericanos afines al Frente Popular. En específico, la DIC actuaría en la aplicación de la legislación social, como regulador del flujo de información transmitido en las radios y otros medios tecnificados, como promotor de la cultura, e incluso como productor en la industria cultural, a través de esfuerzos discográficos, cinematográficos y editoriales. En este despacho confluyeron radicales, demócratas, ibañistas, comunistas, socialistas e independientes, ${ }^{19}$ es decir, un equipo ecléctico e inclinado a una comprensión realista de las necesidades culturales y comunicacionales de la ciudadanía.

Pablo Garrido llegó a ese espacio en 1943 promoviendo, entre otras, la idea que el Estado debía estimular las músicas tradicionales y folclóricas, debido a su importancia histórica y cívica. Según su parecer, la ausencia de medidas en

16 PFG, Escritos Tomo 1. Pablo Garrido, "Hacia una nueva educación ideológica en la música". Multitud, Santiago, febrero, 1939.

17 PFG, Escritos Tomo 1. Pablo Garrido, "Hacia una nueva educación...,".

18 Ministerio del Interior, “Decreto Núm. 35/6331: Fija Atribuciones, funciones y deberes de la Dirección General de Informaciones y Cultura" en Diario Oficial, 19.468, 26 de enero, 1943, p. 1.

19 Donoso, Karen (2021). "“Elevar culturalmente al pueblo'. Chilenidad y cultura popular desde el estado, 19381958”, (manuscrito inédito, Proyecto Fondecyt № 110092 “PPopulismo en Chile? De Ibáñez a Ibáñez”, dirigido por Verónica Valdivia). 
este sentido estaba provocando que el pueblo no conociera su propia cultura. Se lamentaba que las escuelas aún no enseñaban "a amar el canto popular"20 y que no era posible dejar la cultura musical "sin vigilar su factor de educación de una nación, entregándola a manos de quienes no pueden sino seguir una orientación comercial." 21 También se pronunció sobre la situación de la radiodifusión, que consideraba "huérfana de toda vigilancia", a merced de las decisiones de los avisadores, a quienes no les interesaba la sobrevivencia del folclor, pues inundaban la programación con "músicas de cien climas." 22

En síntesis, creía fehacientemente en que el Estado debía proveer las herramientas para asegurar la práctica y conservación del folclor en la población. Y estas ideas fueron las que guiaron su actuar como funcionario de la DIC, donde ocupó dos cargos. El primero en la jefatura del Departamento de Música Popular, donde desarrolló un amplio programa de documentación, registro y difusión de la música popular y tradicional. Dentro de sus actividades se cuentan la realización de los Concursos de Música Popular, con premios en dinero y publicaciones; ${ }^{23}$ la edición de al menos veinticuatro discos de 78 r.p.m. organizados en cinco series, Música Bailable, Música Criolla, Música Documental (grabaciones de música tradicional), Música del Siglo XIX y Música Estilizada, los que fueron presentadas por Garrido como una "empresa desinteresada y dedicada a estampar en la cera o el celuloide las más significativas y modernas composiciones chilenas [...]." ${ }^{24}$

También produjo programas radiales sobre música chilena, transmitidos en cadena nacional, según la programación ordenada por la propia DIC. Pero sus proyectos predilectos y, en definitiva, los que mejor trascendieron fueron la creación de un Archivo Folklórico, el cual pretendía incorporar material audiovisual, sonoro y escrito, relativo a las músicas populares arcaicas. Por cierto, avances en esta materia fueron la producción de documental La Tirana $(1944)^{25}$ y el levantamiento del Censo Folklórico, del cual lamentablemente no ha quedado registro. Bajo su gestión, entonces, avanzó tanto en la intervención

20 FPG, Escritos Tomo 1. Pablo Garrido, “La música popular chilena y la escuela”, El Tarapacá, 25 de mayo, 1941.

21 FPG, Escritos, Tomo 1. Pablo Garrido, "Problemas de nuestra cultura musical", Las Ultimas Noticias, Santiago, 29 de agosto, 1940.

22 FPG, Escritos Tomo 1. Pablo Garrido, "Defendamos el campo. Ausencia de la música popular chilena", Las Ultimas Noticias, 1 de agosto 1940.

23 Dirección General de Informaciones y Cultura (1946). Repertorio de letras para canciones. Santiago: Lagos y Vera Impresores. Una colección de partituras del año 1944 se encuentra en el FPG.

24 FPG. Discos y Música DIC. Ediciones de Discos Sello DIC 1947, (documento mecanografiado) y Grabaciones de danzas y cantos chilenos por el Departamento de Música de la Dirección General de Informaciones y Cultura. Santiago, DIC, 1946.

25 El mediometraje puede ser visionado en el sitio de la Cineteca de la Universidad de Chile. Sin desmerecer sus estrictos méritos cinematográficos, el documental es reflejo tanto de los afanes personales de su director (Garrido fue pionero en la investigación folclórica sobre el Norte Grande, en efecto) como de la política cultural de la DIC, orientada a la producción de material audiovisual sobre cultura popular chilena. 
del Estado en el campo de la música tradicional como de la industria cultural, bajo las nociones promovidas anteriormente.

El segundo de estos cargos, asumido en 1945, fue la jefatura del Departamento de Radio, donde le correspondió aplicar la ordenanza que disponía que la programación radial debía cumplir con al menos un 30\% de música chilena, y que las empresas radiofónicas debían tener un $80 \%$ de artistas y trabajadores nacionales. ${ }^{26}$ Dicha ordenanza obedecía a las demandas del gremio de músicos, al menos desde la década anterior, y debió enfrentar cuestionamientos y desacatos por parte de las emisoras.

En dicha materia, sin ir más lejos, Garrido daba cuenta de sus habilidades como investigador y gestor. En una misiva enviada a Ricardo Vivado, presidente de la Asociación de Radiodifusoras de Chile, respondía a los argumentos de los broadcasters que señalaban que, para cumplir con dichas normativas, no había suficiente música chilena para programar. Garrido adjuntó una reseña histórica sobre la música escrita, grabada y producida en Chile desde el siglo XIX, negando la posibilidad siquiera que el repertorio se acabara en diez días -según alegaba Vivado-. Cabe señalar que la abrumadora cantidad de información citada por Garrido da cuenta de la calidad de Archivo antes mencionado, pero, sobre todo, que él hacía frente al hecho de que las radioemisoras sólo no tenían intención de obedecer la nueva normativa.

\begin{abstract}
"Es curioso $[\ldots]$ ", contraargumenta, "[...] que se haga una afirmación tan enfática, sobre la no existencia de material chileno, cuando, según mis noticias, ni la Facultad de Bellas Artes, ni el Instituto de Extensión Musical, ni el Departamento de Música de la Dirección General de Informaciones y Cultura, ni la Asociación de Compositores (Chile), ni la Sociedad de Compositores de Música de Chile, jamás han sido consultados sobre el repertorio nacional, $y$, según tengo entendido, esas organizaciones estatales y particulares agrupan a investigadores y creadores, letristas y musicólogos, intérpretes y directores de orquestas (desde la música frívola a las altas obras sinfónicas)." 27
\end{abstract}

Debido a diferencias políticas y personales, en 1947 Garrido renunció a sus cargos e inició una estadía en el extranjero que lo mantendría por algunos años alejado de la escena cultural y política nacional. En el intertanto, la DIC fue disuelta por el gobierno de González Videla, desmantelándose estos primeros intentos de institucionalidad cultural estatal, derivando sus funciones hacia otros organismos como la Universidad de Chile y el Ministerio de Educación. ${ }^{28}$

\footnotetext{
26 Ministerio del Interior, "Reglamento de Transmisiones de Radiodifusión”, en Diario Oficial, 22 de noviembre, 1944 p. 10.

27 FPG, Escritos Tomo 2. Las radiodifusoras y el repertorio de música chilena, El Siglo, 28 de marzo 1947.

28 Donoso (2021). “Elevar culturalmente...,".
} 
Luego de una esforzada pero no menos fructífera estadía en los Estados Unidos, Puerto Rico y España, Garrido volvió a Chile a inicios de la década de 1950. A su regreso, se empleó mayoritariamente como periodista y crítico en distintos medios de la capital, como conferencista y ocasionalmente como docente. Recién a mediados de la década de 1960 volvió a ocupar cargos burocráticos, como Coordinador General de la Ópera del Teatro Municipal de Santiago ${ }^{29}$ siendo finalmente llamado en 1971 a ser parte de la comisión que organizó la conferencia UNCTAD III.

Si bien su nombre no figuró dentro de los artistas e intelectuales que apoyaron la campaña de la Unidad Popular, igualmente fue llamado a ocupar un puesto en el Departamento de Cultura de la Secretaría General de la Presidencia. ${ }^{30}$ Como hemos mencionado, en su archivo se observa el interés que presentó por las políticas culturales de los países del bloque del este. Asimismo, realizó atentas lecturas a las obras de los líderes soviéticos y propuso comentarios y reformas a la institucionalidad cultural del gobierno, siguiendo las líneas del programa socialista -que se expresarían ulteriormente en la frustrada fundación del Instituto Nacional de Cultura-. Se pronunció en el gran debate cultural desarrollado en el seno del gobierno de Salvador Allende, en torno a qué tipo de cultura se proyectaría desde el Estado: si aquella conducente al socialismo o bien una anclada a las bases en las prácticas, el imaginario de los sectores populares. ${ }^{31}$ Garrido planteaba que "la política cultural deberá surgir de la ideología del proletariado y no de una administración burocrática, a menos que esta última se organice desde las bases," ${ }^{32}$ por lo tanto, se debían generar instancias para recabar las demandas populares. Para ello, sugería el levantamiento de un Catastro Nacional de organismos culturales; reunir "todos los estatutos, reglamentos, resoluciones, decretos, leyes, disposiciones universitarias, escolares, castrenses, etc. que digan atingencia con aspectos de la cultura y la recreación", y llevar a cabo un gran Parlamento de la Cultura Popular encargado de dirigir el debate y levantar propuestas. ${ }^{33} \mathrm{~A}$ pesar de ello, en febrero de 1973 manifestó su preocupación por la situación que atravesaba el gobierno:

29 FPG. Fernando García Arancibia. “Pablo Garrido...,”. p. 148.

30 FPG, Caja 59. Contrato Pablo Garrido, 1 de enero 1973.

31 Este debate fue reconstruido por Bowen, Martin (2008). "El proyecto sociocultural de la izquierda chilena durante la Unidad Popular. Crítica, verdad e inmunología política", Nuevo Mundo Mundos Nuevos. Otros autores que han abordado esta problemática son: Briceño, Laura (2020). “Escritores intelectuales y la política cultural en el gobierno de Salvador Allende. Los aportes del taller de escritores de la Unidad Popular (19701973)", Revista Izquierdas, 49, pp. 292-311; Canto, Nadine (2012). “El lugar de la cultura en la vía chilena al socialismo. Notas sobre el proyecto estético de la Unidad Popular". Pléyade, 9.

32 FPG, Caja Microfilm. Pablo Garrido. Análisis del proyecto de ley, Instituto Nacional de Cultura (INAC). 21 de junio 1972.

33 FPG, Caja Microfilm. Pablo Garrido Análisis... 
“La situación del país es gravísima. Allende tiene una oposición cerrada de parte de la burguesía, que no puede ver que el pueblo también es ser humano. Hay elecciones generales parlamentarias el cuatro de marzo, y será algo muy reñido, aún cuando gane la oposición. Nadie sabe qué vendrá después. No hay cigarrillos, aceite, carne, te, azúcar, harina, en fin. Algo verdaderamente dramático, forzado por la oposición, es claro."34

De sus papeles se deduce que, tras el golpe de Estado, Garrido fue despedido. Hasta el momento no tenemos antecedentes que haya sufrido persecución política, sin embargo, debe ser considerado un exonerado político. Al año siguiente, Garrido salió del país rumbo a México, para visitar a su familia, pero debió volver abruptamente tras la prematura muerte de su compañero, el violinista Pedro D’Andurain. Los años siguientes los vivió en la pobreza y el aislamiento, componiendo e investigando la mayor parte del tiempo, y asumiendo como tareas principales la reedición de su Biografía de la Cueca y la escritura de una nueva obra.

\section{Nacional y popular: la cueca de Pablo Garrido}

“La vida de una danza nacional es cual la existencia del pueblo mismo, sujeto a vicisitudes, avatares, júbilos, explosiones de fervor.

Porque una danza nacional nace para no morir, no importa bajo qué designios se desenvuelva." ${ }^{35}$

Como se aprecia en el epígrafe de esta sección, ya en 1963 Pablo Garrido se refería a la cueca como "danza nacional". Y lo hizo en reiteradas ocasiones, sin aludir necesariamente a la demanda por un reconocimiento institucional, siendo este, por cierto, uno de los temas investigativos al que dedicó gran parte de sus energías. ¿A qué se refería con dicha referencia? El primer artículo que se ha datado sobre este tema lo publicó en 1928, en el contexto de una polémica avivada por la promoción de una cueca "moderna".

Juan Valero era uno de los más reconocidos intérpretes y maestros de bailes de salón y populares en la época, quien aseguraba que un profesor francés había estrenado en la muestra de danzas de París el Huppa Huppa, una versión de la cueca donde, en vez de bailar en parejas sueltas (como dicta la tradición), se ejecutaba tomándose de manos y cintura, imitando el estilo del tango. ${ }^{36}$ Luego, Valero la tildó de "cueca aristocrática" o "estilizada" y la incorporó a sus clases de baile, al menos entre 1925 y 1928, destacando que era parte de la nueva moda y que se bailaba en los mejores salones europeos. Esta innovación coincidía

34 FPG, Caja 72. Carta de Pablo Garrido a Juan Garrido, Santiago 20 de febrero 1973.

35 FPG, Caja 71. Biografía de la Cueca. 10 programas radiales. 1963 (manuscrito mecanografiado).

36 "Nuestro baile nacional, la "cueca" y su influencia internacional", Los Tiempos, 3 de marzo, 1925, p. 14. 
con el inicio de las grabaciones discográficas en el país y, de hecho, la prensa destacaba que "gracias a la introducción de esta nueva danza se ha fomentado la producción de música criolla, la que imprimirá en discos la Casa Víctor."37

Tanto las publicaciones como la presencia de esta danza en los espacios recreativos de la elite nacional, provocaron fuertes críticas de mano de escritores y columnistas de la prensa periódica. Se cuestionó que esto era sólo una "ola nacionalista" y no existía un interés por relevar el "amplio y rico folklore musical" que "todavía está casi virgen." ${ }^{38}$ Asimismo, se levantaron varias voces señalando que la cueca no debía ser reformada. El compositor y director del Conservatorio de Música Popular Javier Rengifo, ${ }^{39}$ señaló que:

“[...] si la cueca se bailara tal como es, no solamente sería elegante, sería majestuosa. La labor que debemos realizar, es propagar y enseñar la verdadera cueca, con todas sus figuras y su sentido de las diferentes regiones, pues cada aspecto sirve para interpretar el alma de cada región." 40

Garrido se incorporó a esta polémica criticando a los "chilenos reaccionarios" que sólo aceptaban músicas si eran anunciadas como "nuevas", informando además que la cueca en el extranjero sí era novedosa, de modo que no había necesidad de añadirle un nuevo apelativo. Asimismo, destacó que la gran potencialidad que ofrecía la cueca en términos musicales era su ritmo. ${ }^{41}$ Tres años después y estando fuera del país, se volvió a pronunciar sobre este tema, señalando que la cueca sería expresión del mundo popular celebrando a la patria:

"El pueblo se viste de gala y en parques y avenidas se alzan las típicas "ramadas" donde las "empanadas de horno", "pequenes" y "cazuelas de ave" procuran el optimismo que ha de llegar a su clímax con el quisquilloso riego de la sabrosa "chicha" y el "vino tinto". Entonces es cuando el "roto" pide instintivamente su baile nativo: la "cueca." 42

Los extractos referidos dan cuenta de que Garrido incorporaba argumentos folclóricos para abordar la cueca, ponderándola ya no sólo como un género vigente y ampliamente practicado, sino como una expresión "auténticamente"

37 Los Tiempos, 25 de septiembre, 1925, p. 15; “La cueca el mejor baile de salón”, Los Tiempos, 9 de diciembre, 1927 p. 7; "La cueca chilena estilizada está llamada a competir y aún desplazar al tango argentino”, Los Tiempos, 14 de abril 1928, p. 11.

38 "Música Chilena", Los Tiempos, 3 de mayo 1928, p. 5.

39 "Armonía absoluta encontramos en el Conservatorio de Javier", Los Tiempos 2 de abril, 1929, p. 8.

40 "La cueca moderna", Los Tiempos, 15 de febrero, 1929, p. 5.

41 FPG, Pablo Garrido, Impongamos la cueca, El Mercurio de Valparaíso, 18 de marzo, 1928.

42 FPG, Escritos Tomo 1. Pablo Garrido, Evocación del alma musical del pueblo de Chile, La Antena, Panamá, 18 de septiembre, 1931. 
popular. Asimismo, planteó que su carácter nacional estaba dado por que, aunque los "caballeros" o los sectores altos la negaran, no podían desentenderse de ella:

"Y es el "huaso" que llevamos a todos adentro en no sé qué rincón de nuestras almas, el que se nos subleva en esos días de exaltación patria. Es el recuerdo de una guitarra y una voz familiar que allá en el fondo de nuestra niñez nos arrullara con sus "tonadas" tristes o sus "cuecas" picarescas -es ese súbito despertar de nuestra conciencia lo que nos arroja intempestivamente el ardor del fuego nativo- [...] y bailamos y cantamos hasta quedar exhaustos, cuando ya el firmamento da paso a los primeros rayos del sol de septiembre, abatidos por el supra esfuerzo físico, aún cuando el alma pide más cantos, cuando los ojos se han extasiado en imaginarios rincones de las montañas y campiñas sureñas, cuando entre cueca y cueca hemos traído a memoria algún "18" con "topeaduras" y "rodeos" en algún extraviado "fundo" del sur lejano y aromado, o en el norte trágico con su pampa salitrera de fabulosas e ignoradas leyendas $[\ldots] . " 43$

Así, Garrido daba inicio a sus escritos sobre folclor, consolidados en este caso en su libro Biografía de la cueca, publicado por Editorial Ercilla en 1943, la primera monografía dedicada a esta expresión. Esta obra reforzó varios de los argumentos planteados anteriormente. En primera instancia, defendió el carácter popular de su práctica: "no falta la cueca, pues, en cumpleaños, santos, bautizos, cambios de argolla, matrimonios, malones, esquinazos, tijerales, rodeos, topeaduras", en fiestas íntimas y domésticas, pero también en fiestas colectivas: "la faena de mar y de la tierra, en la gesta bravía donde se precisa un corazón bien puesto y ser hombre de "pelo en pecho", o incluso en el "circo criollo", y en la Procesión marítima de San Pedro. ${ }^{44}$

También planteó que los versos de la cueca reflejaban el ánimo y la identidad popular: "no hay tema que la cueca no aborde, entendido que en ellos puedan desarrollarse ampliamente la fantasía y la chispa populares. Nunca mejor que en los versos de la cueca para encontrarnos el ingenio de nuestro pueblo." 45 Asimismo, señaló que "a pesar que se ganó el rechazo de la aristocracia por la "relajación de las costumbres", fue en la segunda mitad del siglo XIX que consolidó su "raigambre popular y contenido libertario". Y reforzando su carácter de clase, reconoció en el huaso, la china y el roto a sus personajes clave toda vez que "la cueca parece ser más cueca cuando es bailada por el "huaso." 46

FPG, Escritos Tomo 1. Pablo Garrido, Evocación del alma...

Garrido, Pablo (1943). Biografía de la Cueca, Santiago: Ed. Ercilla, p. 90.

45 Garrido (1943). Biografía... p. 84.

46 Garrido (1943). Biografía... p. 97. 
Así, Garrido se sumó a quienes promovieron la cueca como una expresión "auténticamente nacional". Esto estaba dado porque a pesar del desprecio de la elite, la cueca logró convertirse en la forma transversal de conservar el "espíritu patriótico", ${ }^{47}$ planteando que "no hay chileno que no sienta el llamado de la tierra, la voz de la altiva cordillera y la evocación del pasado glorioso, al oír sus incitantes ritmos." ${ }^{48}$ La cueca estaba presente en todo el territorio nacional "(...) junto a la trilla, confundida con la faena campera; está marginando la corrida de vacas, las carreras "a la chilena", las topeaduras; fiestas de proeza y gallardía. La cueca pertenece a cada una de las prendas del huaso (...) la cueca labra la tierra." ${ }^{49}$

Finalmente, Garrido aseguró en este libro que la cueca, tal como se conocía en ese entonces, con esa forma poética y rítmica, con ese tipo de coreografía e interpretación corporal, había sido gestada en territorio chileno en el siglo XIX: “después de milagrosos serpenteos por tres continentes, robando o pidiendo prestado aquello que sospecha habrá de hacerla más arrogante y seductora en este suelo identifica una raza, y, por ello, Chile y Cueca son una sola y la misma cosa." ${ }^{50}$ La carta de ciudadanía estaba dada por su gestación, sin embargo, Garrido fue enfático en reconocer que -a diferencia de lo planteado por otros autores- en la cueca no era posible desconocer las herencias arábigas, andaluzas $\mathrm{y}$ afrodescendientes.

Para sostener el último argumento, utilizó una serie de documentos históricos, dialogando con cada cronista que hizo referencia a danzas populares. Así, cuestionó a José Zapiola por referirse escuetamente a la zamacueca en sus memorias, por manifestar un "divorcio con la expresión popular" y buscar convencer a los lectores que esta danza tenía un origen peruano. ${ }^{51}$ Asimismo, retomó los planteamientos de Benjamín Vicuña Mackenna, quien atribuye al "lariete" -una danza que vio practicada por un grupo de africanos esclavizados en Quillota-, como un precedente de la zamacueca. ${ }^{52}$

En definitiva, para Garrido la cueca era una expresión popular porque fue conservada y difundida por los sectores plebeyos; pero también era nacional, ya que se practicaba en distintos lugares del país y si se observaba su origen, se apreciaba que se tenía múltiples herencias culturales pero la forma que se practicaba en 1943, se habría gestado en territorio nacional, debatiendo con Carlos Vega quien propuso su dispersión latinoamericana y estableció vínculos con la marinera peruana y la cueca cuyana. De esta forma, Garrido transita

\footnotetext{
Garrido (1943). Biografía... p. 76.

Garrido (1943). Biografía... p. 109.

Garrido (1943). Biografía... p. 109.

Garrido (1943). Biografía... p. 110.

Garrido (1943). Biografía... p. 24.

Garrido (1943). Biografía... p. 45-46.
} 
entre la crítica empírica a las fuentes y la incorporación de determinados esencialismos propios de la época: ${ }^{53}$ mientras asegura que no se pueden determinar los orígenes de esta expresión por la multiplicidad de culturas que confluyeron en América Latina, asegura que la cueca es auténticamente chilena, sin pronunciarse sobre la contradicción que esto pudiese encarnar. Asimismo, defendió a ultranza la tesis de la herencia africana y dedicó las décadas siguientes a respaldarla, esperando remover el ambiente académico e intelectual chileno.

Uno de esos cuestionamientos provino del escritor Hernán Díaz Arrieta, alias Alone, quien acusó a Garrido de ejercer un "prejuicio partidista aferrado a la lucha de clases". Llegó a preguntarse "¿en qué se funda el autor para sostener que la clase alta aborrece la cueca y ha intentado proscribirla? Suponemos que no será la frase de Portales, por él mismo citada, y tan famosa "No cambiaría una zamacueca por la presidencia." 54

Asimismo, le espetó estar obsesionado con romper el vínculo cultural con España, a pesar de que "la música no es solamente la música: es el alma, es la lengua, es la tradición, y el temperamento íntimo; y cuanto en tal esfera dominó, pese a los indoamericanistas, no fue lo indígena ni lo negro - por nuestra suertesino lo español." ${ }^{55}$

En las décadas siguientes, Garrido continuó reuniendo información sobre esta materia. En su Fondo se conservan una serie de manuscritos de versos recopilados en distintos puntos del país, partituras, apuntes bibliográficos, fotocopias, fotografías, e incluso el guion de un programa de radio donde reunió decenas de efemérides relativas a la cueca, tanto en su interpretación musical como su evidencia de práctica. Allí se aprecia que la herencia africana en Chile era uno de los temas que intentó promover, e incluso, causar polémica y discusiones con otros investigadores. A uno de sus hermanos, confesó que:

"Los "historiadores" racistas y los anteriores "memorialistas" coloniales (hispánicos y criollos) no ofrecen asidero para mensurar hasta qué grado el influjo afroide perfiló nuestra vida social, en mil maneras. Así es que hay que hilar muy delgado, leer entrelíneas, ver "debajo del alquitrán" y hasta imaginar, la argumentación que presume contundencia, ya que el milagro musical o propiamente rítmico, es asunto que no conmueve a los hombres de pluma que historian o describen (...) Sobre Chile, ya no me

53 El tema es teóricamente abordado por algunos textos, sean los casos de, por ejemplo, Donoso, Karen (2006). La Batalla del Folklore: los conflictos por la representación de la cultura popular chilena en el siglo XX. Tesis para optar al grado académico de Licenciada en Historia. Universidad de Santiago, Santiago, p. 173.; Ramos, Ignacio (2011). "Construcciones y disputas en torno a lo mestizo: Canto a lo Poeta y Bailes Chinos en Chile Central, del folklore a la diversidad cultural", Revista Chilena de Literatura (miscelánea virtual) 78, pp. 1-31.

54 FPG, Caja 39. "Crónica Literaria, Biografía de la Cueca", El Mercurio, 1 de agosto, 1943, p. 3.

55 FPG, Caja 39. "Crónica Literaria, Biografía de la Cueca", El Mercurio, 1 de agosto, 1943, p. 3. 
cabe duda que ejercieron una influencia grande. Pero, la pregunta sería otra: ¿acaso en España, con anterioridad a la Conquista de América, el negro no participó en la vida social?"56

Esa larga investigación decantó en primer lugar en la reedición de Biografía de la Cueca, que terminó de escribir en el verano de 1973. Mantuvo el título y sus capítulos, pero alteró notoriamente el contenido: incorporó más bibliografía, por lo tanto, más argumentos y descripciones, cambió la redacción casi completa del texto, pero mantuvo incólume sus hipótesis, a pesar de los treinta años de distancia. Deben ser, en consecuencia, ambas ediciones consideradas libros aparte. Sobre su origen y las polémicas desatadas por la tesis de su afrodescendencia, enfatizó que:

“No se diga, pues, que la zamacueca nos vino del África, que allí jamás se bailó. Toda danza vernácula es lenguaje, y cual éste su riqueza radica en los influjos exógenos que le dan a su vertebración particularidades que tipifican, paradojalmente, a los pueblos que aparecen como sus usuarios. Porque, después de todo, una danza como bien cultural, es patrimonio de quien se identifica con él." ${ }^{157}$

"Pero su identidad es una sola: chilena. No hubo zamacuecas ni cuecas en el África ni en España, por consiguiente, no nos vino de fuera. Es, pues, el símbolo más puro de nuestra identidad." ${ }^{58}$

\section{El Historial de la Cueca y un Decreto ley.}

El 18 de septiembre de 1979, Pablo Garrido llegó hasta el Salón Azul del Edificio Diego Portales, la misma infraestructura creada para la realización de la UNCTAD III, ahora ocupada como oficinas gubernamentales tras el bombardeo a La Moneda. Allí se realizó una ceremonia donde el general Pinochet firmó el Decreto Supremo № 23 del Ministerio Secretaría General de Gobierno, que declaraba a la cueca "danza nacional de Chile". Éste habría sido una demanda elaborada por la Federación Nacional de la Cueca (FENAC) y habría llegado hasta el despacho presidencial de mano de funcionarios cercanos a los cuequeros. $^{59}$

La normativa atribuía ese rango, pues esta expresión "constituye la más genuina expresión del alma nacional", "se ha identificado con el pueblo chileno desde los albores de la independencia" y es una expresión de "auténtica

56 FPG, Caja 72. Carta de Pablo Garrido a Juan Garrido, Santiago 20 de febrero 1973.

57 Garrido, Pablo (1976). Biografía de la cueca. Santiago: Editorial Nacimiento, pp. 77-78.

58 Garrido (1976). Biografía..., p. 103.

59 "La cueca está de cumpleaños", Proyección de la Cultura, Secretaría Nacional de Relaciones Culturales, 15 de septiembre, 1989, p. 16. 
unidad." ${ }^{60}$ Tras la firma, Garrido recibió de manos del general Pinochet un ejemplar autografiado de su Historial de la Cueca, proclamado públicamente como una obra patrocinada por el Estado.

Siendo este un acto representativo del imaginario cultural de la dictadura, habría que explicar la presencia allí de Garrido y su obra. Según su propio testimonio, tras el golpe de Estado y la muerte de su compañero Pedro D'Andurain, cayó en un delicado estado de salud. Sin trabajo ni ingresos, su familia lo ayudaba a solventar sus gastos. En sus memorias reconoce que su primo Jorge Cornejo le brindaba manutención y le prestaba vivienda, y en sus cartas y documentos personales se da cuenta que desde 1975 recibió aporte económico de sus familiares en el extranjero. Este fue un problema que lo acompañó hasta sus últimos días. ${ }^{61}$

Por ello, volver a publicar sus obras y escritos se presentó como una posibilidad de terminar con esas subvenciones. De esta forma, redactó columnas para el periódico Las Ultimas Noticias, abandonando los temas contemporáneos y musicales para recurrir casi exclusivamente a temas históricos. ${ }^{62}$ Intentó publicar sus libros El Mejor Amigo, dedicado a trescientos perros y sus dueños famosos, y la biografía de Pedro D'Andurain, sin resultados. Pero, por otro lado, Editorial Nascimento le pidió que terminara la revisión de Biografía de la Cueca, cuya segunda versión había entregado en 1973 y publicado en septiembre de 1976, aunque sus afanes estaban puestos en el Historial de la cueca.

El primer manuscrito fue entregado a Ediciones Universidad Católica de Valparaíso a mediados de 1976, siendo aceptado en marzo de 1977. ${ }^{63}$ Se le pidió realizar algunos cambios, por ejemplo, suprimir un capítulo titulado "Laberinto amerindio" que pasaría a ser apéndice, finalmente descartado. También cambió el título a algunos capítulos y escribió una presentación, pues se le criticó que su tesis era demasiado críptica. ${ }^{64}$ De hecho, en este nuevo manuscrito, Garrido fue mucho menos directo -con respecto a la Biografía- en su definición de la cueca. El Historial trata muy poco de la expresión misma y se dedica, más bien, a discutir las fuentes documentales que registraron su práctica en el siglo XIX y las evidencias utilizadas por otros investigadores. El libro lo dividió en tres partes:

60 Ministerio Secretaría General de Gobierno, "Decreto Supremo 23, Declara a la cueca danza nacional de Chile", Diario Oficial, 6 de noviembre, 1979, p. 4.

61 FPG, Caja 46, Carpeta 1. Pablo Garrido, Memorias 1974-1976, 1977.

62 FPG, Caja 46, Carpeta 1. Pablo Garrido, Memorias 1974-1976, 1977).

63 FPG, Caja 39, Carpeta Historial de la Cueca. Carta de Renato Carmona a Pablo Garrido, Valparaíso 18 de marzo 1977; y Carta de Renato Carmona a Pablo Garrido, Valparaíso 30 de marzo 1977.

64 FPG, Caja 39, Carpeta Historial de la Cueca. Carta de Pablo Garrido a Renato Carmona, Santiago, 26 de marzo 1977. 
La primera fue destinada a debatir con investigadores y cronistas que se aventuraron a presentar una tesis sobre el origen de la cueca. Garrido no estaba de acuerdo con esa búsqueda pues creía que esta manifestación surgió del crisol cultural chileno (y americano), producto de la "confluencia de tres culturas que, admitámoslo o no, conforman nuestra nacionalidad -amerindia, hispánica, africana- ya eran, a la hora de la Conquista, summa de culturas milenarias en sus propios hábitats." 65

En la segunda parte, se dedicó a ilustrar las prácticas culturales populares, que reconoció como principal preservación de la cueca. Sin embargo, en esta ocasión no se refiere a sus practicantes como "el pueblo", sino que lo denomina "el estado llano", alocución llamativa, dado el contexto y la trayectoria del autor. Como sujetos representativos reconoce al "roto" y al "huaso" aunque se queda con el primero, a quien identifica como el difusor de la cueca por América, ${ }^{66}$ exaltándolo por su capacidad creativa. Desde ese lugar, debatió puntualmente la teoría de la "folclorización" de Carlos Vega, planteando que no era posible asociar las manifestaciones culturales populares al "descenso" de las prácticas de las elites, sino que también era posible observar análogas expresiones artísticas en diferentes territorios, lo que asoció con las tesis del "paralelismo cultural." ${ }^{67}$ Evitando el lenguaje clasista presente en su primer libro, Garrido volvió sobre el tema de la condición social del huaso y el roto, dando cuenta que en su cultura y expresiones artísticas es posible ver mecanismos de resistencia: “La inevitable sumisión del estado llano -consecuencia de instancias ya borrosas pero que gravitaron en el subconsciente colectivo de la plebe- le despierta gradualmente a la realidad de un faenar sin hado. Porque aun medrando del muelle estar del "señor" -en la villa o en la campiña- está virtualmente marginado de un escalamiento social que le liberaría de la dependencia." 68

En la tercera parte, es donde más abordó la cueca misma, centrándose en las crónicas y la prensa del siglo XIX. Con esas fuentes la ubicó como manifestación propia de los espacios populares -como chinganas y teatros- pero también fue dando cuenta del proceso complejo de reconocimiento institucional. Concluyó su obra citando a Pablo de Rokha, quien -ahora sí- sin fuentes ni fundamentos históricos, situó a la cueca como una danza interpretada por José Miguel Carrera (es decir, antes de 1814), concluyendo que la cueca es la danza nacional por excelencia, ya que existiría desde los albores de la nación.

Es decir, ya no sólo era calificada como popular y nacional, sino que también republicana. De esta forma, concluyó el libro con una estrategia contradictoria, toda vez que dedicó varios capítulos a desmenuzar las huellas

65 Garrido, Pablo (1979), Historial de la Cueca. Valparaíso: Ediciones Universidad Católica de Valparaíso, p. 193.

66 Garrido (1979), Historial..., p. 91.

67 Garrido (1979). Historial..., p. 53

68 Garrido (1979). Historial..., p. 85. 
y la idoneidad de las fuentes utilizadas por otros autores, para desarmar las tesis del origen peruano. Pero no cuestionó estos párrafos escritos por el poeta en 1958, curiosamente, cayendo una vez más en la esencialización de esta práctica. También se aprecia que, si bien insistió en generar polémica al instalar con fuerza la afrodescendencia de la cueca, este texto no fue tan explícito con respecto a su condición de clase, como la primera edición de la Biografía. Acá Garrido se jugó por demostrar que sus antecedentes históricos acreditaban la auténtica chilenidad de esta expresión.

La diagramación del texto estuvo lista en $1978,{ }^{69}$ aunque la publicación sufrió un retraso debido a la muerte su primo Jorge, que lo afectó emocionalmente y le obligó a mudarse de casa. A esa situación se sumó un accidente que redujo su movilidad. Con todo, en junio de ese año firmó el contrato de edición (por un total de diez mil ejemplares, de los cuales recibiría el 10\% del precio de venta), ${ }^{70}$ y en diciembre recibió las pruebas de imprenta finales, entregando sus correcciones en enero de 1979. ${ }^{71}$ Estos datos indican que el libro y el vínculo contractual estaba listo mucho antes de septiembre de 1979, de modo que no hubo vinculación inicial a una iniciativa gubernamental.

Sin embargo, el editor le indicó que "para ser justos, [la edición] fue posible por una intervención directa del presidente, ya que ciertos personajes de menor cuantía intentaron bombardearlo."72 Garrido respondió que "sólo tu espíritu abierto -lo intuyo- pudo salvar quizás cuántos escollos. Y entiendo, además, la mucha devoción y reciedumbre artística de tus colaboradores todos."73 Con esta información nos preguntamos ¿quiénes intentaron obstruir la publicación? $\mathrm{Y}$, ante todo ¿porqué recibió el patrocinio presidencial? En los documentos del Fondo no aparecen antecedentes que permitan aclarar estas interrogantes. Cabe señalar que, en ese contexto, la dictadura había impuesto un estricto procedimiento de censura a la edición, a manos de la Dirección Nacional de Comunicación Social. ${ }^{74}$ Por lo tanto, es dable sospechar que fue en esa instancia donde se encontraron trabas.

Sin embargo, otros aparatos culturales desplegaron programas de acción donde el folclor y la cueca tuvieron un lugar privilegiado. De ellos se destaca

69 FPG, Caja 39, Carpeta Historial de la Cueca. Carta de Renato Carmona a Pablo Garrido, Valparaíso, 9 de diciembre 1977 y Carta de Luis Briones a Pablo Garrido, Valparaíso, 8 de marzo 1978.

7o FPG, Caja 39, Carpeta Historial de la Cueca. Contrato de Edición, Valparaíso 1 de junio 1978.

71 FPG, Caja 39, Carpeta Historial de la Cueca. Carta de Luis Briones a Pablo Garrido, Valparaíso, 13 de diciembre 1978" y "Carta de Pablo Garrido a Luis Briones, Santiago, 4 de enero 1979; y Carta de Chelo a Pablo Garrido, México 17 de enero 1979", en Caja 72, FPG.

72 FPG, Caja 39, Carpeta Historial de la Cueca. Carta de Renato Carmona a Pablo Garrido, Santiago, 10 de septiembre 1979 .

73 FPG, Caja 39, Carpeta Historial de la Cueca. Carta de Pablo Garrido a Renato Carmona, Santiago, 25 de septiembre 1979.

74 Donoso, Karen (2019). Cultura y dictadura. Censuras, proyectos e institucionalidad cultural en Chile, 19731989. Santiago: Ed. Universidad Alberto Hurtado, p. 57. 
la Secretaría de Relaciones Culturales del Ministerio Secretaría General de Gobierno, que si bien recibió como responsabilidad la legislación cultural, en la segunda mitad de la década de 1970, emprendió proyectos de divulgación artística. ${ }^{75}$ Dentro de sus actividades se encuentran la realización de concursos de poesía, cuento, teatro y artes plásticas, de programas radiales, de ferias de artesanía y capacitación de artesanos. ${ }^{76}$ Bajo la jefatura de Benjamín Mackenna (1977-1980), integrante del conjunto Los Huasos Quincheros, la Secretaría incrementó su intervención en el ámbito del folclor. Creó un concurso de música que concluyó en la edición de un cassette y patrocinó programas de televisión, festivales y concursos de artes visuales. Según se ha dado cuenta, esta oficina promovió una perspectiva nacionalista y conservadora sobre el arte y la cultura, que implicó el reconocimiento del folclor en una versión tradicionalista, concebido como disposiciones esenciales de la nación y matriz de una auténtica y originaria identidad nacional. ${ }^{77}$

De esta forma, tras la depuración ideológica del ambiente artístico tras el golpe de Estado, las actividades de la Secretaría estuvieron orientadas a fomentar y patrocinar actividades de artistas y agrupaciones adherentes a la dictadura, o bien que representaran su concepto cultural. ${ }^{78}$ Bajo esa lógica, a partir de 1977 auspiciaron algunos certámenes del Campeonato Nacional de Cueca y del Congreso de Estudio y Muestra de la Cueca, organizados por la FENAC. ${ }^{79}$ Asimismo, el propio Mackenna habría sido parte de las gestiones que posibilitaron la promulgación del Decreto, ${ }^{80}$ financiando además la impresión de mil ejemplares de Historial de la Cueca. En su presentación, Mackenna dio cuenta de las ideas que buscaba promover la dictadura en el campo de lo folclórico:

“El Supremo Gobierno ha manifestado en reiteradas oportunidades su interés y preocupación por proteger y consolidar los valores, principios, hábitos y tradiciones que configuran el alma del ser nacional, siendo uno de ellos precisamente, la manifestación de un folklore genuino y auténtico. Por ello esta Secretaría de Relaciones Culturales considera digna del mayor encomio la iniciativa del autor de esta obra, que permitirá, a través de un mayor conocimiento de nuestra danza nacional, adoptar las medidas que permitan darle la importancia que merece." ${ }^{\prime 1}$

75 Donoso (2019) Cultura y dictadura..., p. 192; Jara, Isabel (2016). “Nacionalismo y política artística-cultural de la dictadura chilena: la Secretaría de Relaciones Culturales" en Nuevo Mundo Mundos Nuevos, 2016, (Consultado el 15 de marzo 2021).

76 Jara (2016). “Nacionalismo y política...,” párrafo 21.

77 Donoso, Karen (2009). "Por el arte-vida del pueblo. Debates en torno al folclor en Chile. 1973-1990" en Revista Musical Chilena, (LXIII, 212), p. 33.

78 Donoso (2019). Cultura y dictadura..., p. 194.

79 León, Carlos (2018). Competencia y chilenidad: los campeonatos de cueca huasa en Chile: 1965-1992. Tesis presentada para optar al grado de Magíster en Historia, Universidad de Concepción, p. 110.

80 León, Carlos (2018). Competencia y chilenidad..., p. 112.

81 Pablo Garrido, Historial de la Cueca, "Página sin foliar". Citado en: León, Carlos (2018). + p. 118. 
En sus cartas personales, se aprecia que la noticia del auspicio tomó a Garrido desprevenido. Al pintor Pedro Olmos, quien facilitó una de sus pinturas para la portada del libro, le manifestó que: "para mí fue una sorpresa encontrarme que mi libro aparecía bajo un patrocinio determinado, pues de eso jamás se habló ni mucho menos concertó contractualmente. Pero ¡salió!" 82 Como contraparte, Garrido verbalizó que tenía esperanzas en recibir de manera directa el pago por los derechos autorales correspondientes a esos mil ejemplares, aunque no sabía si esto estaba estipulado en el contrato o sería contabilizado aparte. Además, la asociación de su publicación con el Decreto de la cueca, le permitió tener mayor presencia en medios de comunicación, y así lo confesó a su familia:

“El librito me ha dado no sólo canas, sino actualización; pero para mí resulta todo fofo, sin consonancias, aunque con muchas resonancias. No me refiero a la parte económica -que tendré que llegar algún día- sino a la promoción personal. Me han hecho entrevistas en TV, Radio, prensa y qué se yos." ${ }^{\prime 84}$

En sus documentos no logramos encontrar su impresión respecto a la situación política: no era adherente a la dictadura, pero tampoco se unía a la resistencia cultural. Sí se le vio muy cercano a la FENAC, con quienes participó en diversos eventos patrocinados institucionalmente, como el Campeonato Nacional de Cueca de Arica, en junio de $1979,{ }^{85}$ y el III Encuentro Nacional Diego Portales de la Cueca en Graneros, en agosto del mismo año (donde fue nombrado socio honorario del Club de Huasos Clodomiro Barril de Rancagua). Hallamos cartas intercambiadas con dirigentes de esta entidad, como Hernán Hurtado, con quienes comentó las desventuras de la publicación del Historial y las implicaciones de Decreto 23. Estaba preocupado por el devenir de la cueca siendo promovida por la Federación, y en consecuencia presentó a Mackenna un plan de acción para hacer efectivo lo prometido por el Decreto. Sugería difundir la cueca como "carta de ciudadanía, mediante la exaltación de los valores patrios, históricos, culturales y espirituales" y desarraigar los "preconceptos de la práctica referida tan sólo a efemérides, uso de indumentaria determinada y estereotipo formal." 86 Asimismo, pensaba que se debía conformar un equipo consultivo que abordara tanto la historia como la música y la danza de la cueca, y creara materiales didácticos. Para ello, sugirió la concurrencia de la FENAC en ese equipo y que se descartara la competencia de los concursos de cueca escolares. ${ }^{87}$

82 FPG, Caja 72. Carta de Pablo Garrido a Pedro Olmos, Santiago 5 de octubre 1979.

33 A propósito, Garrido señaló que "no me he visto con la gente de la Editorial (...) de modo que para mí es todo un enigma el destino que tendrá la concertada edición de 10.000 ejemplares. Pero he escrito hoy, averiguando pormenores" en FPG, Caja 72. Carta de Pablo Garrido a Miguel Gutiérrez, Santiago 7 de octubre 1979.

84 FPG, Caja 72. Carta de Pablo Garrido a Chelito y Freddie, Santiago, 24 de octubre 1979.

85 FPG, Caja 72. Carta de Hernán Hurtado a Pablo Garrido, Arica 2 de marzo 1979.

86 Ambas citas en FPG, Caja 72. Carta de Pablo Garrido a Benjamín Mackenna, Santiago, Santiago, 30 de octubre 1979.

87 FPG, Caja 72. Carta de Pablo Garrido a Benjamín Mackenna... 
El Secretario de Relaciones Culturales, por su parte, incorporó a Garrido dentro de un homenaje a quienes habían aportado a la música chilena. Pero, estos reconocimientos no lo confortaban si no incluían una retribución económica:

"El Gobierno me ha distinguido el jueves 25 último, "reconociendo" mi labor de toda una vida en pro de la música chilena, otorgándome públicamente un DIPLOMA (!). Ya antes, el 18 de septiembre, el presidente, al firmar el Decreto declarando "danza nacional" a la Cueca, me hizo entrega personalmente, en acto oficial de mi libro editado por el Gobierno (!). Honores y nada más." ${ }^{88}$

Un mes después de entregado este reconocimiento, le comentaba a su ahijada Amparo sus planes:

"pienso emigrar, quizás a España, donde podría agenciar la publicación de seis libros y hacer representar mis operas. Si tengo éxito en la venta, pienso pasar por New York, donde se han hecho gestiones con la NBC para una versión TV de mi ópera en un acto: THE TRAIL OF MAN, y, claro que me gustaría poder saludarles de paso. Pero "soñar no cuesta nada", y es bonito, sin embargo ¿no te parece?" 89

Así, con la idea de radicarse en el extranjero, Garrido comenzó a organizar su archivo y biblioteca para venderlos. En paralelo, sondeó posibilidades de dictar conferencias en Perú y Bolivia, donde solicitó alojamiento y alguna remuneración. También intentó conseguir una beca para concluir una investigación sobre Ramón Carnicer en España. Todas estas gestiones fueron infructuosas. Su situación empeoró cuando, a mediados de 1980, debió abandonar su residencia y "arrumbar todo mi tremendo Archivo, regalar mi biblioteca por \$5.000 y arrimarme por “comprensión" en casa de unos amigos." Con todo, reclamó nuevamente el pago de sus derechos a la editorial. Suponía que el gobierno había comprado mil ejemplares y esperaba recibir al menos el $10 \%$ de esa adquisición. Y reclamó en varias ocasiones la demora en los pagos correspondientes por contrato. ${ }^{91}$

A esas alturas, dependía no sólo de lo que le enviaba su familia desde el extranjero sino también del apoyo económico brindado por un grupo de amigos,

88 FPG, Caja 72. Carta de Pablo Garrido a Amparo, Santiago, 27 de octubre 1979. Las mayúsculas y signos de exclamación pertenecen al texto original.

89 FPG, Caja 72. Carta de Pablo Garrido a Amparo, Santiago, 27 de octubre 1979.

90 FPG, Caja 39, Carpeta Historial de la Cueca. Carta de Pablo Garrido a Renato Carmona, Santiago, 24 de mayo 1980.

91 FPG, Caja 72. Carta de Pablo Garrido a Manuel Salazar, Santiago, 30 de octubre 1979 y Carta de Pablo Garrido a Richard, Santiago, 30 de octubre 1979. En carta al editor, le preguntó expresamente qué sucedió con los ejemplares que compró el gobierno, respondiéndole que esos fueron los únicos que se editaron. FPG, Caja 39, Carpeta Historial de la Cueca. Carta de Pablo Garrido a Renato Carmona, Santiago 5 de octubre 1979. 
liderado por Margot Loyola. Sin embargo, su esperanza siguió en irse del país, para lo cual solicitó a la editorial saldar los derechos de autor, e incluso que a cambio le compraran pasajes a España..$^{22}$ Finalmente, en octubre de 1980 le entregaron su liquidación: sus ganancias eran $\$ 4.590$ por derechos de autor y 75 ejemplares, correspondiente al 10\% de la cantidad que quedaban, de 2.106 que se imprimieron. ${ }^{93}$

Luego de este episodio, Garrido no obtuvo otro reconocimiento oficial. Postuló infructuosamente al Premio Municipal de Literatura y Premio Nacional de Arte y luego de fracasar reuniendo presupuesto para salir del país, solicitó una pensión de gracia ante Pinochet, argumentando que "soy músico, escritor e investigador de nuestras tradiciones. Desde los dieciocho años me he hecho el deber de difundir los valores patrios, tanto en el país como en el exterior", y que a sus "setenta y cinco años de edad, no cuento con previsión alguna y el estado de mi salud es precaria debido a la temprana amputación de una de mis extremidades." ${ }^{94}$ La pensión le fue concedida dos años después, en junio de 1982, falleciendo Garrido apenas tres meses más tarde. ${ }^{95}$

\section{CONCLUSIONES}

Pablo Garrido Vargas fue uno de los intelectuales más incidentes en el debate por la definición del folclor chileno y, a su vez, por la caracterización y definición de la cueca chilena. Sus obras son lectura obligada para el mundo de la danza y la música de dicha expresión, y su intento por visibilizar la presencia africana en la cultura chilena ha tenido especial eco en los últimos veinte años. Sin embargo, por muchos años su figura fue excluida de la historia de la música académica chilena, y resurgió sólo cuando la musicología se dedicó a manifestaciones populares. Por lo señalado, este artículo tuvo como fin visibilizar el pensamiento y accionar de Garrido, dando cuenta de su trayectoria intelectual que estuvo atravesada por sus conflictos vitales.

Sobre el nudo problemático, se ha podido demostrar el compromiso de Garrido con las propuestas de política cultural enarbolada por la izquierda y el centro político, siendo un actor clave en los gobiernos del Frente Popular y de la Unidad Popular. A pesar de esto, no actuó como un intelectual opuesto a la dictadura civil militar instalada, sino que sorteó su última década de vida entre la cesantía y los intentos por radicarse en el extranjero. Por ello, postulamos que el investigador no sólo accedió al patrocinio institucional, sino que también

92 FPG, Caja 39, Carpeta Historial de la Cueca. Carta de Pablo Garrido a Renato Carmona, Santiago, 24 de mayo 1980.

93 FPG, Caja 39, Carpeta Historial de la Cueca. Liquidación de derechos. 16 de octubre 1980 y Guía de despacho, 11 de noviembre 1980.

94 FPG, Caja 72. Carta de Pablo Garrido a Augusto Pinochet. Santiago, 26 de septiembre 1980.

95 FPG, Caja 53. Sobre una solicitud de pensión de gracia de Pablo Garrido. Santiago, 10 de agosto 1981. 
flexibilizó su posición con respecto a la cultura chilena, lo que se aprecia incluso en el cambio de lenguaje utilizado en Historial de la Cueca.

$\mathrm{Su}$ trinchera, en ese entonces, ya no estuvo puesta en el reconocimiento de la cueca como expresión plebeya, sino en la tesis de la afrodescendencia, la cual podría resultar polémica (aunque no censurable) para un régimen, como es sabido, profundamente anticomunista.

Asimismo, el vínculo que estableció Garrido con organizaciones como la FENAC benefició la consideración de funcionarios como Benjamín Mackenna, principal artífice tanto del financiamiento de su obra como del Decreto № 23 . Para Garrido, la Federación era una organización que estaba recién surgiendo, y si bien tuvo el beneplácito del gobierno, aún se encontraba en el proceso de posicionarse frente a la práctica de la cueca, los clubes y torneos.

Como contraparte, estimamos que, a partir de los antecedentes expuestos, es patente que el patrocinio institucional al Historial de la Cueca se trató de un reconocimiento coyuntural a la obra de Pablo Garrido, y no a su persona. La Secretaría de Relaciones Culturales incorporó este acto dentro de sus actividades, donde el folclor tuvo un lugar privilegiado durante la jefatura de Mackenna. El carácter despolitizado y nacionalista del Decreto propuesto por la FENAC, así como su propuesta cultural, fueron acogidos favorablemente por la oficina gubernamental. En ese contexto, el libro Historial de la Cueca resultó un proyecto adecuado a los lineamientos institucionales. 


\section{FUENTES}

\section{Documentos}

Dirección General de Informaciones y Cultura (1946). Repertorio de letras para canciones. Santiago: Lagos y Vera Impresores.

Ministerio del Interior, “Decreto Núm. 35/6331: Fija Atribuciones, funciones y deberes de la Dirección General de Informaciones y Cultura" en Diario Oficial, 19.468. 26 de enero, 1943.

Ministerio del Interior, "Reglamento de Transmisiones de Radiodifusión", en Diario Oficial, 22 de noviembre, 1944, p. 10.

Ministerio Secretaría General de Gobierno, “Decreto Supremo 23, Declara a la cueca danza nacional de Chile", Diario Oficial, 6 de noviembre 1979, p. 4.

\section{Archivos}

Facultad de Artes, Universidad de Chile. Fondo Pablo Garrido (FPG).

\section{BIBLIOGRAFÍA}

Bowen, Martin (2008). "El proyecto sociocultural de la izquierda chilena durante la Unidad Popular. Crítica, verdad e inmunología política" , Nuevo Mundo, Mundos Nuevos.

https://journals.openedition.org/nuevomundo/13732 Consultado el 15 de marzo 2021.

Briceño, Laura (2020). “Escritores intelectuales y la política cultural en el gobierno de Salvador Allende. Los aportes del taller de escritores de la Unidad Popular (1970-1973)", Revista Izquierdas, 49. pp. 292-311.

Canto, Nadine (2012). "El lugar de la cultura en la vía chilena al socialismo. Notas sobre el proyecto estético de la Unidad Popular". Pléyade, 9.

Donoso, Karen (2021). “'Elevar culturalmente al pueblo'. Chilenidad y cultura popular desde el Estado, 1938-1958", (manuscrito inédito, Proyecto Fondecyt № 110092 “¿Populismo en Chile? De Ibáñez a Ibáñez” dirigido por Verónica Valdivia).

Donoso, Karen (2019). Cultura y dictadura. Censuras, proyectos e institucionalidad cultural en Chile, 1973-1989. Santiago: Ed. Universidad Alberto Hurtado. 
Donoso, Karen (2009). "Por el arte-vida del pueblo. Debates en torno al folclor en Chile. 1973-1990", Revista Musical Chilena, (LXIII, 212), p. 33.

Donoso, Karen (2006). La Batalla del Folklore: los conflictos por la representación de la cultura popular chilena en el siglo XX. Tesis para optar al grado académico de Licenciada en Historia. Universidad de Santiago. Santiago.

González, Juan Pablo (1983). “Cronología epistolar de Pablo Garrido”, Revista Musical Chilena, XXXVII, 160, pp. 4-46.

Cabello, Pablo (2020). Historia del jazz en Valparaíso: los albores (1920-1934). Tesis para optar al grado de Magíster en Historia. Valparaíso, Pontificia Universidad Católica de Valparaíso, 2020.

Garcés, Mario (2018). El movimiento obrero y el Frente Popular (1936-1939). Santiago: Editorial Lom, p. 125.

Garrido, Pablo (1940). Tragedia del músico chileno. Santiago: Editorial Smirnow.

Garrido, Pablo (1943). Biografía de la Cueca, Santiago: Editorial. Ercilla.

Garrido, Pablo (1976). Biografía de la cueca. Santiago: Editorial Nascimento.

Garrido, Pablo (1979). Historial de la Cueca. Valparaíso: Ediciones Universidad Católica de Valparaíso.

Jara, Isabel (2016). “Nacionalismo y política artística-cultural de la dictadura chilena: la Secretaría de Relaciones Culturales". Nuevo Mundo Mundos Nuevos.

https://journals.openedition.org/nuevomundo/68967 Consultado el 15 de marzo 2021.

Karmy, Eileen (2019). The path to trade unionism: musical work in Chile (18931940). Tesis para optar al Grado de Doctora en Filosofía. Universidad de Glasgow, Glasgow.

León, Carlos (2018). Competencia y chilenidad: los campeonatos de cueca huasa en Chile: 1965-1992. Tesis presentada para optar al grado de Magíster en Historia, Universidad de Concepción.

Menanteau, Álvaro (2006). Historia del Jazz en Chile. Santiago: Ocho Libros Editores. 
La Cueca según Pablo Garrido: Entre el compromiso Político-Cultural y un decreto dictatorial (1928-1979)

La Cueca according to Pablo Garrido: Between the Political-Cultural commitment and a dictatorial decree (1928-1979)

Moraga, Fabio y Carla Peñaloza (2011). “España en el corazón de los chilenos. La alianza de intelectuales y la revista Aurora de Chile, 1937-1939", Anuario Colombiano de Historia Social y de la Cultura, 38, 2, pp. 55-81. Consultado el 2 de marzo 2021.

Ory, Pascal y Sirinelli, Jean-Francois (2007). Los intelectuales en Francia. Del caso Dreyfrus a nuestros días, Valencia: Ed. PUV, pp. 20-21.

Ramos, Ignacio (2011). “Construcciones y disputas en torno a lo mestizo: Canto a lo Poeta y Bailes Chinos en Chile Central, del folklore a la diversidad cultural", Revista Chilena de Literatura (miscelánea virtual) 78, pp. 1-31. Consultado el 15 de marzo 2021. 